\title{
Southern Ocean sea-ice extent, productivity and iron flux over the past eight glacial cycles
}

E. W. Wolff, H. Fischer, F. Fundel, U. Ruth, B. Twarloh, G. C. Littot, R. Mulvaney, R. Röthlisberger, M. de Angelis, C. F. Boutron,

M. Hansson, U. Jonsell, M. A. Hutterli, F. Lambert, P. Kaufmann, B. Stauffer, T. F. Stocker, J. P. Steffensen, M. Bigler,

M. L. Siggaard-Andersen, R. Udisti, S. Becagli, E. Castellano,

M. Severi, D. Wagenbach, C. Barbante, P. Gabrielli \& V. Gaspari

Nature 440, 491-496 (2006); doi:10.1038/nature04614.

In calculating the fluxes used in this paper, we made a mistake in the snow accumulation rate used. We calculated fluxes assuming that snow accumulation rates were expressed in metres water equivalent, but they were actually expressed in metres ice equivalent. The result of this error is that the fluxes shown in the original paper are uniformly $8.3 \%$ too high. The shape of the affected plots (the lower four panels in Figure 2, both panels in Figure 3, and the top and bottom panels in Figure 4) remains the same if the correct values are plotted, and the affected figures could be corrected by re-scaling the y-axes by $8.3 \%$. Our conclusions are not affected. The flux data in the Supplementary Information of the original paper ('Supplementary Data 2') have now been corrected. 